\title{
Climatologies from satellite measurements: the impact of orbital sampling on the standard error of the mean
}

\author{
M. Toohey ${ }^{1}$ and T. von Clarmann ${ }^{2}$ \\ ${ }^{1}$ GEOMAR Helmholtz-Centre for Ocean Research Kiel, Kiel, Germany \\ ${ }^{2}$ Karlsruhe Institute of Technology, Institute for Meteorology and Climate Research, Karlsruhe, Germany \\ Correspondence to: M. Toohey (mtoohey@ geomar.de) \\ Received: 31 October 2012 - Published in Atmos. Meas. Tech. Discuss.: 9 November 2012 \\ Revised: 19 February 2013 - Accepted: 10 March 2013 - Published: 10 April 2013
}

\begin{abstract}
Climatologies of atmospheric observations are often produced by binning measurements according to latitude and calculating zonal means. The uncertainty in these climatological means is characterised by the standard error of the mean (SEM). However, the usual estimator of the SEM, i.e., the sample standard deviation divided by the square root of the sample size, holds only for uncorrelated randomly sampled measurements. Measurements of the atmospheric state along a satellite orbit cannot always be considered as independent because (a) the time-space interval between two nearest observations is often smaller than the typical scale of variations in the atmospheric state, and (b) the regular time-space sampling pattern of a satellite instrument strongly deviates from random sampling. We have developed a numerical experiment where global chemical fields from a chemistry climate model are sampled according to real sampling patterns of satellite-borne instruments. As case studies, the model fields are sampled using sampling patterns of the Michelson Interferometer for Passive Atmospheric Sounding (MIPAS) and Atmospheric Chemistry Experiment Fourier-Transform Spectrometer (ACE-FTS) satellite instruments. Through an iterative subsampling technique, and by incorporating information on the random errors of the MIPAS and ACE-FTS measurements, we produce empirical estimates of the standard error of monthly mean zonal mean model $\mathrm{O}_{3}$ in $5^{\circ}$ latitude bins. We find that generally the classic SEM estimator is a conservative estimate of the SEM, i.e., the empirical SEM is often less than or approximately equal to the classic estimate. Exceptions occur only when natural variability is larger than the random measurement error, and specifically in instances where the zonal sampling distribution shows non-uniformity with a similar zonal structure as
\end{abstract}

variations in the sampled field, leading to maximum sensitivity to arbitrary phase shifts between the sample distribution and sampled field. The occurrence of such instances is thus very sensitive to slight changes in the sampling distribution, and to the variations in the measured field. This study highlights the need for caution in the interpretation of the oft-used classically computed SEM, and outlines a relatively simple methodology that can be used to assess one component of the uncertainty in monthly mean zonal mean climatologies produced from measurements from satellite-borne instruments.

\section{Introduction}

Atmospheric observations are often averaged within timespace intervals, such as calendar months and latitude bands, producing so-called "climatologies" (e.g., Grooß and Russell III, 2005; Hegglin and Tegtmeier, 2011; von Clarmann et al., 2012). While the motives behind the construction of such climatologies can be simply pragmatic for instance to simplify comparison with similarly averaged model fields - averaging does have the advantageous effect of reducing the impact of random variations present in individual measurements due to measurement errors and natural variability. The standard error of the mean (SEM) is a statistical quantity which quantifies the random error in the calculated mean value.

In general terms, the standard error describes the random error of an estimate based on limited sampling of a population. For example, the SEM describes the potential variation of a sample mean of $n$ samples if other, equally probably sets of $n$ samples were drawn instead. The "classic" and oft-used 
SEM estimator is given by the standard deviation of the sample divided by the square root of the sample size, however, this estimator is only valid when the measurements are uncorrelated. Consideration of correlations of measured data is a standard in various applications of statistical estimators inferred from atmospheric measurements, e.g., Jones et al. (1997) consider inter-site correlations in the estimation of global mean temperatures; Weatherhead et al. (1998) present a scheme to consider autocorrelations in estimating uncertainties in trends; and von Clarmann et al. (2010) propose a generic approach to consider arbitrary correlations in trend estimation. For the SEM, one of the most fundamental estimators of a finite sample of atmospheric data, little literature is available.

Correlations in atmospheric measurement sets depend upon the underlying time-space correlations of the atmosphere, and the time-space sampling patterns of the measurements themselves. Observational datasets from satellite instruments have distinct sampling patterns which depend on the orbit and measurement technique of the instrument. Different sampling patterns can lead to differences in the means of two datasets: in this case, the difference is referred to as a sampling bias. For example, Aghedo et al. (2011) have examined the role of sampling in biasing monthly mean values of satellite-based measurements of tropospheric chemical species and temperature. However, the potential impact that sampling may have on the SEM of atmospheric climatologies has not, to our knowledge, been formally addressed.

The goals of the present study are (1) to raise awareness of the potential impact of sampling on the SEM of climatologies built from satellite-based atmospheric measurement sets, (2) to develop a strategy for estimating the magnitude of its impact, and finally (3) to estimate the impact that sampling considerations have on the SEM for some sample cases. In order to assess the impact of time-space sampling patterns on the SEM, we present a numerical recipe which makes use of model fields from a coupled chemistry climate model. Assuming that the model accurately reproduces, in a statistical sense, the correlations of the true atmosphere on scales larger than the horizontal footprint of the satellite measurements, results from this experiment can be used to draw some general statements about the quality of the SEM estimates usually produced from measurements.

\section{Theory and methodology}

Given a set of $N$ measurements $x_{n}$, the sample mean $\bar{x}$ and sample standard deviation $\hat{\sigma}_{x}$ are calculated as

$\bar{x}=\frac{\sum_{n=1}^{N} x_{n}}{N}$

and

$\hat{\sigma}_{x}=\sqrt{\frac{\sum_{n=1}^{N}\left(x_{i}-\bar{x}\right)^{2}}{(N-1)}}$ respectively. The sample mean is an estimate of the population mean, while the sample standard deviation characterises the scatter of the measured data and, thus, includes both the natural variability within the population and the measurement error. The sample mean is intentionally calculated without consideration of any predicted measurement error for weighting purposes, since measurement errors can be a function of geolocation and, thus, could bias the mean: e.g., measurement errors of gases measured by infrared emission are usually smaller when the atmosphere is warmer, and inverse weighting of the measurements by the measurement error variance would bias the sample mean, so that it is more representative for the warmer parts of the atmosphere.

Each single measurement differs from the sample mean by some amount due to natural variability and measurement error. Treating each such deviation as an "error", and the sample standard deviation as an estimate of the average "error", the calculation of the SEM follows directly from generalised Gaussian error propagation:

$$
\begin{aligned}
\mathrm{SEM}^{2} & =\left(\frac{1}{N}, \ldots, \frac{1}{N}\right)\left(\begin{array}{ccc}
\hat{\sigma}_{x}^{2}, & \ldots, & r_{1, N} \hat{\sigma}_{x}^{2} \\
\vdots & \ddots, & \vdots \\
r_{N, 1} \hat{\sigma}_{x}^{2}, & \ldots, & \hat{\sigma}_{x}^{2}
\end{array}\right)\left(\begin{array}{c}
\frac{1}{N} \\
\vdots \\
\frac{1}{N}
\end{array}\right) \\
& =\hat{\sigma}_{x}^{2}\left(\frac{1+(N-1) \bar{r}}{N}\right),
\end{aligned}
$$

where $r_{i, j}$ is the correlation between measurements $x_{i}$ and $x_{j}$, and $\bar{r}$ is the average correlation coefficient between the measurements of the sample (cf. Jones et al., 1997). Defining

$k=\sqrt{1+(N-1) \bar{r}}$,

the SEM can be written as

$\mathrm{SEM}=\frac{\hat{\sigma}_{x}}{\sqrt{N}} k$.

With $\bar{r}=0$, i.e., independent uncorrelated measurements (both in terms of measurement error and natural variability), $k=1$ and the expression for the SEM simplifies to its common estimator $\hat{\sigma}_{x} / \sqrt{N}$. When the average correlation between measurements is positive, $k>1$ and the SEM is greater than $\hat{\sigma}_{x} / \sqrt{N}$, i.e., the usual estimator which assumes independent measurements can be seen to underestimate the true SEM. Likewise, when the average correlation between measurements is negative (but not less than $-1 /(N-1)$ ), $0<k<1$ and the usual estimator, $\hat{\sigma}_{x} / \sqrt{N}$, is an overestimate of the true SEM.

Since the variance of the measurements is due to both natural variability and to measurement noise, the SEM reflects both sources of variance. Assuming that measurement individual error $\left(\epsilon_{i}\right)$ of any individual measurement $\left(x_{i}\right)$ is uncorrelated with the true atmospheric state $\left(\tau_{i}\right)$, the variance of any measurement set $\hat{\sigma}_{x}^{2}$ is equal to the sum of the variances of the truth and the measurement error:

$\hat{\sigma}_{x}^{2}=\sigma_{\tau}^{2}+\sigma_{\epsilon}^{2}$. 
Under these standard assumptions, the SEM can be similarly decomposed into components reflecting uncertainty in the mean due to natural and measurement error variability:

$\mathrm{SEM}^{2}=\mathrm{SEM}_{\tau}^{2}+\mathrm{SEM}_{\epsilon}^{2}$.

In situations where $\mathrm{SEM}_{\epsilon}^{2} \gg \mathrm{SEM}_{\tau}^{2}$, i.e., where retrievals have large random errors or where the natural variability is small, the SEM reflects the uncertainty in the mean due to the random measurement error. Random measurement errors are by definition uncorrelated, therefore, the mean correlations between measurements should be negligible and the classic SEM estimator is valid in this case. In the other limiting case, where $\mathrm{SEM}_{\tau}^{2} \gg \mathrm{SEM}_{\epsilon}^{2}$, correlations between measurements are impacted by the patterns of variability within the atmosphere, leading to the possibility that correlations between measurements affect the SEM.

In this paper, we indirectly assess the role of the mean correlation coefficient $\bar{r}$ between measurements, for example satellite-borne instrument sampling patterns. We do so by producing an empirical estimate of the SEM. Here we take advantage of the fact that the SEM can be defined as the standard deviation of all possible sample means (of a given size) drawn from the population. Firstly, we subsample model fields based on the sampling pattern of a satellite instrument. Leaving aside (for the moment) measurement error, each sample of the model data can be thought of as a true value $\left(\tau_{i}\right)$ for the location of the sample. Sample means for each latitude bin are calculated from the subsampled model data for this sampling pattern. Then, we produce an "equivalent" sampling pattern, which reproduces the most important features of the sampling (latitude and local solar time), but is randomly shifted in longitude (and universal time such that local solar time is held constant). Each such equivalent sampling pattern can be thought of as resulting from a satellite instrument which has the exact same orbit as the original, except with a different position along the orbit at any point in time. Performing the equivalent sampling a number of times $(J)$, we produce an ensemble of equally probable sample means for each bin $\left(\bar{\tau}_{j}\right)$. The expected value of the sample mean $\left\langle\bar{\tau}_{j}\right\rangle$ is taken to be the ensemble mean of the sample means, the error of each ensemble mean is, thus, $\bar{\tau}_{j}-\left\langle\bar{\tau}_{j}\right\rangle$ and the SEM is:

$\operatorname{SEM}_{\tau}^{2}=\sum_{j=1}^{J} \frac{\left(\bar{\tau}_{j}-\left\langle\bar{\tau}_{j}\right\rangle\right)^{2}}{J-1}$.

Another option would be to replace the expectation value $\left\langle\bar{\tau}_{j}\right\rangle$ in Eq. (9) by the true average of all modelled values in the latitude/time bin under consideration. In this case, the resulting standard error of the mean would also include any potential sampling bias, while our analysis aims at the assessment of the random error.

Since correlations between the random errors of measurements should be negligible, the random error component of the SEM can be easily calculated as
$\mathrm{SEM}_{\epsilon}^{2}=\frac{\sigma_{\epsilon}^{2}}{N}$,

thus, in order to estimate the total SEM for any instrument dataset, one requires an estimate of the SEM due to sampling of the atmosphere's natural variability (through the resampling exercise and Eq. (9) and knowledge of the random uncertainty in the measurements, given as the error variance $\sigma_{\epsilon}^{2}$.

The magnitude of the impact of correlations on the SEM will be quantified by computing values of $k$ through Eq. (6), by taking the ratio of the empirical SEM and a classic SEM estimator. Substituting Eqs. (7), (8) and (10) into Eq. (6), we can estimate $k$ based on quantities described above as:

$k^{2}=\frac{\operatorname{SEM}_{\tau}^{2}+\sigma_{\epsilon}^{2} / N}{\sigma_{\tau}^{2} / N+\sigma_{\epsilon}^{2} / N}$.

\section{Case Studies}

\subsection{Data}

\subsubsection{MIPAS sampling}

The Michelson Interferometer for Passive Atmospheric Sounding (MIPAS) was a mid-infrared Fourier transform limb emission spectrometer designed and operated for measurement of atmospheric trace species from space (Fischer et al., 2008). MIPAS passed the equator in a southerly direction at 10:00 local time 14.3 times a day, observing the atmosphere during day and night with global coverage from pole to pole.

Two different sampling patterns from the MIPAS mission are used here. From July 2002 to March 2004, MIPAS operated at full spectral resolution, and recorded profiles of limb spectra every $90 \mathrm{~s}$, corresponding to an along-track sampling of approximately $500 \mathrm{~km}$, providing about 1000 vertical profiles per day in its standard observation mode. The latitudes of each MIPAS profile spectra were nominally fixed, i.e., for the majority of orbits, profiles were repeatedly measured at specific latitudes. The sampling pattern associated with this period of high spectral resolution MIPAS measurements is referred to as MIPAS-HR.

Due to problems with the interferometer mirror slide system, MIPAS performed few operations from April to December 2004. In January 2005 regular observations resumed, but with reduced spectral resolution. Lower spectral resolution measurements take less time to perform and, as a result, vertical and horizontal measurement frequency was increased during this time period compared to the former high-spectral resolution period, with horizontal measurement density increasing by about $20 \%$. The latitudes of measured profiles were not fixed during this period. The sampling pattern for this period of low spectral resolution measurements is referred to as MIPAS-LR. (Note that the identifiers HR and LR 
refer to high and low spectral resolution, respectively, which correspond in contrast to low and high time-space sample resolution, respectively.)

We have taken actual measurement locations for MIPAS measurements from 13 January-17 February 2003 and 22 December 2008-26 January 2009 as example sample patterns for MIPAS-HR and MIPAS-LR periods, respectively. Since there are no drastic differences between the month-tomonth sampling patterns of MIPAS (aside from the change between the HR and LR sampling patterns), the sampling patterns from these time periods have been used to define the example sampling patterns for all calendar months for the two periods. It should be noted that since these are actual measurement locations, there are some deviations from the nominal sampling patterns, e.g., sample locations removed because of poor data quality or retrieval problems.

Sampling characteristics for the MIPAS sampling patterns are shown in Figs. 1 and 2. Example daily sample locations for MIPAS-HR (Fig. 1a) span $87.10^{\circ} \mathrm{S}$ to $89.25^{\circ} \mathrm{N}$ latitude, with approximately 1000 sample locations per day. Over a full month of sampling, around 800 samples are collected within $5^{\circ}$ latitude bins (Fig. 1b). Since the latitudinal spacing of consecutive measurements is approximately $5^{\circ}$ (median difference of $4.77^{\circ}$ ), consecutive measurements are generally not grouped into the same latitude bin (exceptions occurring within the $5-10^{\circ} \mathrm{N}$ and $85-90^{\circ} \mathrm{N}$ bins), therefore, consecutive measurements within one latitude bin occur during ascending and descending portions of a single orbit and, as a result, the longitude spacing between consecutive measurements within one latitude bin is approximately $180^{\circ}$ longitude (median difference of $177^{\circ}$ ). Taking an example latitude bin, $55-60^{\circ} \mathrm{N}$, Fig. 1c shows the time (decimal Julian day) versus longitude sampling pattern, which shows remarkable uniformity. A histogram of sample count per $30^{\circ}$ longitude bin for the $55-60^{\circ} \mathrm{N}$ latitude bin shows a uniform distribution of longitudinal sampling (Fig. 1d), with between 60 and 70 samples per $30^{\circ}$ longitude bin. A similar uniformity of sampling pattern is found in the example Southern Hemisphere (SH) latitude bin of 55-60 $\mathrm{S}$ (Fig. 1e, f).

For MIPAS-LR sampling, samples are more closely spaced in time and space, and no longer fixed to certain latitudes. The number of monthly samples within $5^{\circ}$ latitude bins is around 1000 (Fig. 2b), with some variation from bin to bin due to the more random nature of the latitudinal sampling. Since the time-space distance between samples is less than for the MIPAS-HR sampling case $\left(3.6^{\circ}\right.$ latitude median difference between consecutive samples), consecutive measurements from the MIPAS orbit are occasionally binned within a single $5^{\circ}$ latitude bin. For example, approximately $1 / 4$ of samples within the $55-60^{\circ} \mathrm{N}$ latitude bin are "double samples", i.e., two samples with small differences in time and space between them. In some cases, double samples within a latitude bin occur preferentially within certain longitude ranges, leading to non-uniformity in the monthly zonal sample distribution. This is the case, for example, in
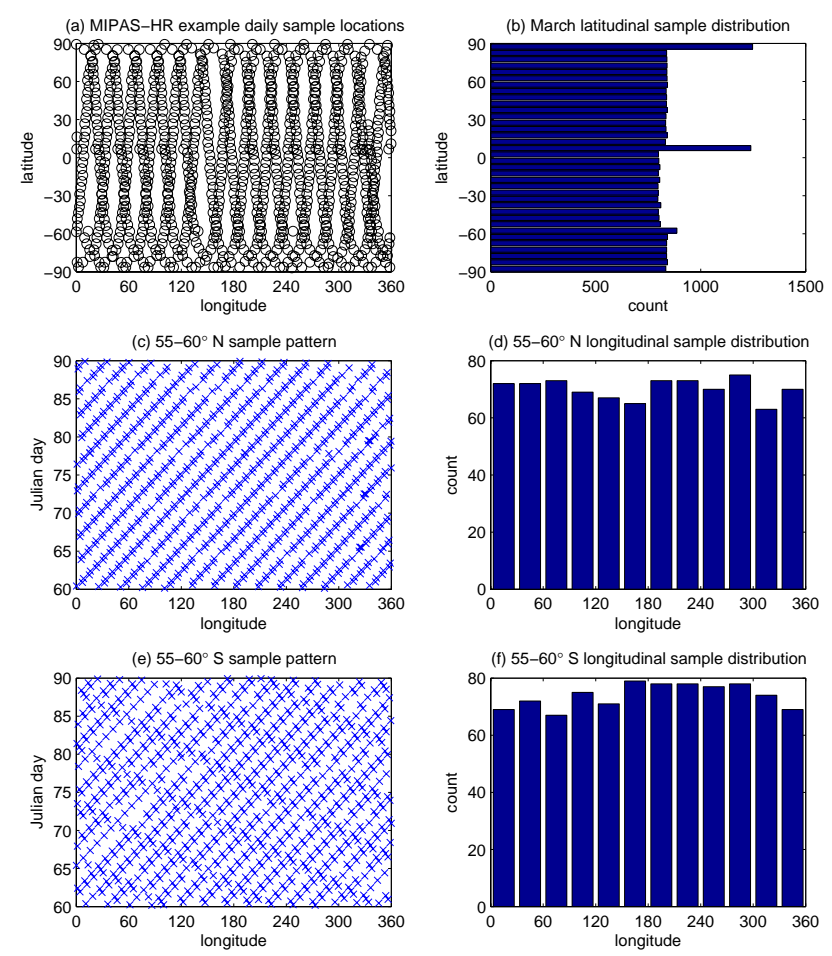

Fig. 1. MIPAS-HR March sampling, approximating MIPAS sampling over the time interval July 2002 to March 2004. (a) Example daily sampling spatial pattern, (b) monthly sample counts per $5^{\circ}$ latitude bin, (c) time, longitude pattern of samples and (d) zonal sample distribution for the $55-60^{\circ} \mathrm{N}$ latitude bin, (e) time, longitude pattern of samples and (f) zonal sample distribution for the $55-60^{\circ} \mathrm{S}$ latitude bin.

the $55-60^{\circ} \mathrm{S}$ bin (Fig. 2e, f), with a notable excess of samples in the Eastern Hemisphere (0-180 longitude). Within the $55-60^{\circ} \mathrm{N}$ bin, however, the double samples are more randomly (and uniformly) distributed (Fig. 2c), and the resulting zonal sample distribution (Fig. 2d) is of similar uniformity as that of MIPAS-HR.

\subsubsection{ACE-FTS sampling}

The Atmospheric Chemistry Experiment-Fourier Transform Spectrometer (ACE-FTS), on board the SCISAT-1 satellite, uses mid-infrared solar occultation to investigate the chemical composition of the atmosphere (Bernath et al., 2005). The SCISAT-1 satellite was launched on 12 August 2003 and began routine measurements on 21 February 2004. The ACEFTS measures approximately 15 sunrise and 15 sunset occultations per day. A high inclination $\left(74^{\circ}\right)$, circular low-earth orbit $(650 \mathrm{~km})$ leads to global coverage of ACE-FTS measurements, but almost $50 \%$ of the occultation measurements made by the ACE-FTS are at latitudes of $60^{\circ}$ and higher. The latitudes of the ACE-FTS sunrise and sunset samples vary with time: global latitude coverage is achieved over a period of approximately three months. 

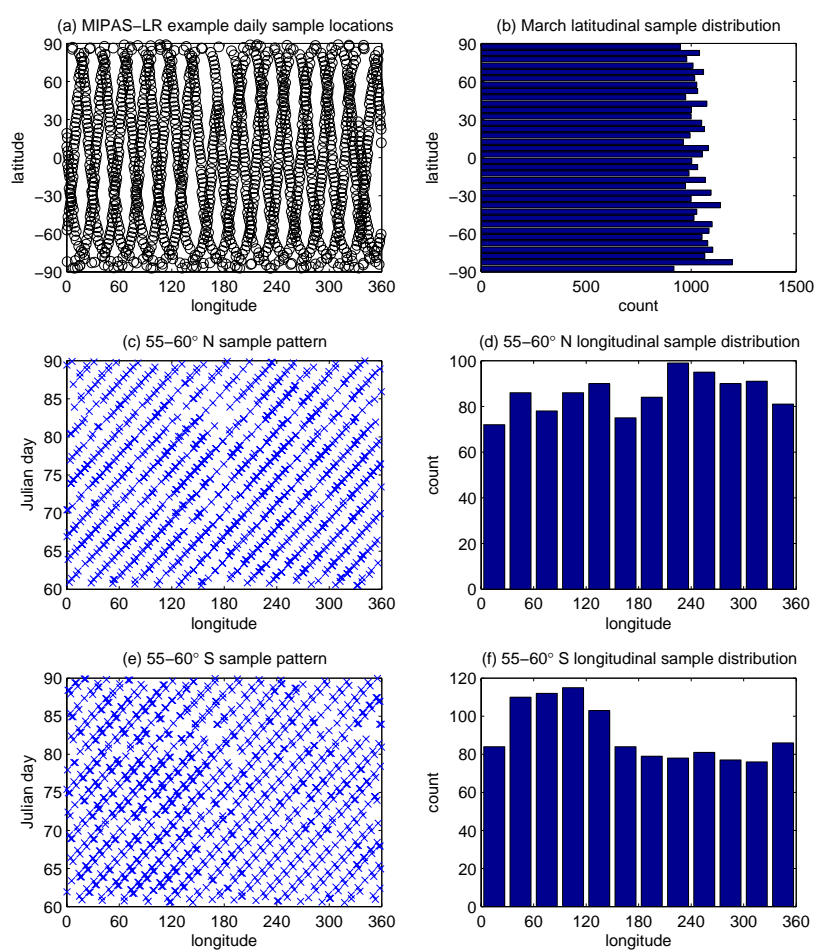

Fig. 2. MIPAS-LR March sampling, approximating MIPAS sampling from January 2005 until mission conclusion. (a) Example daily sampling spatial pattern, (b) monthly sample counts per $5^{\circ}$ latitude bin, (c) time, longitude pattern of samples and (d) zonal sample distribution for the $55-60^{\circ} \mathrm{N}$ latitude bin, (e) time, longitude pattern of samples and (f) zonal sample distribution for the $55-60^{\circ} \mathrm{S}$ latitude bin.

For the sampling exercise presented here, we use the ACEFTS sampling locations from the year 2005, and examine the months March and April as example cases - March gives reasonable coverage of both the southern and northern mid- and high-latitudes, while April sampling covers the tropics and subtropics. Characteristics of the sample patterns for ACEFTS in March and April are shown in Figs. 3 and 4. For March, highest sample density is found in the high latitudes, which is a product of design, the ACE mission being focused on obtaining measurements during the polar winters and springs when $\mathrm{O}_{3}$ destruction chemical processes are underway (Bernath et al., 2005). Sample counts within $5^{\circ}$ latitude bins for March range between $\sim 10$ to $\sim 80$ depending on latitude within this month. For the example latitude bin of 55-60 N, ACE-FTS samples are collected over a few days near the end of the month (Fig. 3c) while in the $55-60^{\circ} \mathrm{S}$ bin, ACE-FTS samples are collected over a few days at the beginning of the month (Fig. 3e). Within this time frame, the samples circle the Earth in terms of longitude, and the distribution of longitudes sampled is, thus, relatively uniform given such small sample size, (Fig. 3d, f), with non-uniformity occurring because of missing measurements or overlap of longitudinal sampling cycles. At latitudes higher than the
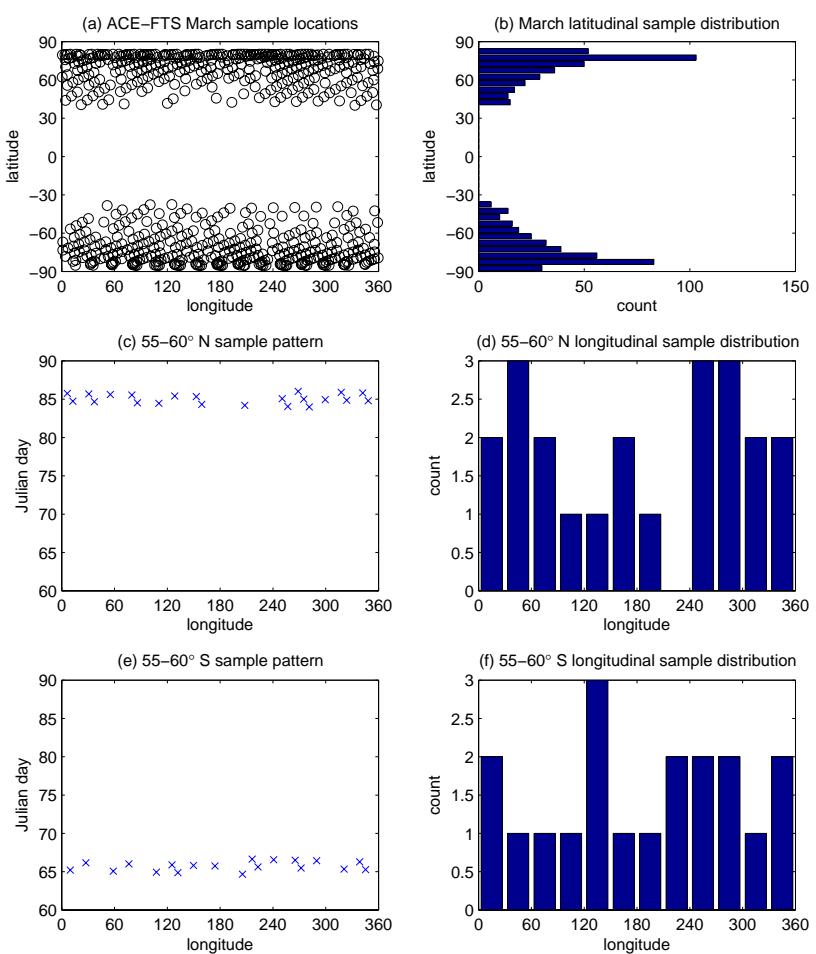

Fig. 3. ACE-FTS sampling in March 2005. (a) Full monthly sampling spatial pattern, (b) monthly sample counts per $5^{\circ}$ latitude bin, (c) time, longitude pattern of samples and (d) zonal sample distribution for the $55-60^{\circ} \mathrm{N}$ latitude bin, (e) time, longitude pattern of samples and (f) zonal sample distribution for the $55-60^{\circ} \mathrm{S}$ latitude bin.

$55-60^{\circ}$ bands shown here, sampling density increases substantially (Fig. 3b), and the zonal distributions become more uniform, while at lower latitudes, the opposite is true.

In April, the ACE-FTS sunrise and sunset sampling patterns cross through the tropics (Fig. 4a). Taking $15-20^{\circ} \mathrm{N}$ as an example latitude bin in the tropics, we see that samples for this bin are composed of measurements at the beginning and end of the month (Fig. 4c). The longitude spacing between consecutive measurements is nominally $24.5^{\circ}$, and samples are collected in this bin over $\sim 2$ days, long enough for the samples to cover the full zonal band, leading to 2 or more samples within 9 out of the $1230^{\circ}$ longitude bins shown in Fig. 4d. There are also a handful of samples within April in the SH high latitudes. Taking the example band of $70-75^{\circ} \mathrm{S}$, these samples are collected near the end of April (Fig. 4e), and are notably non-uniform in their longitudinal distribution (Fig. 4f).

\subsubsection{Model fields}

The CMAM is an extended version of the Canadian Centre for Climate Modelling and Analysis spectral general circulation model. The dynamical core and chemistry scheme are described by Beagley et al. (1997) and de Grandpré et al. 

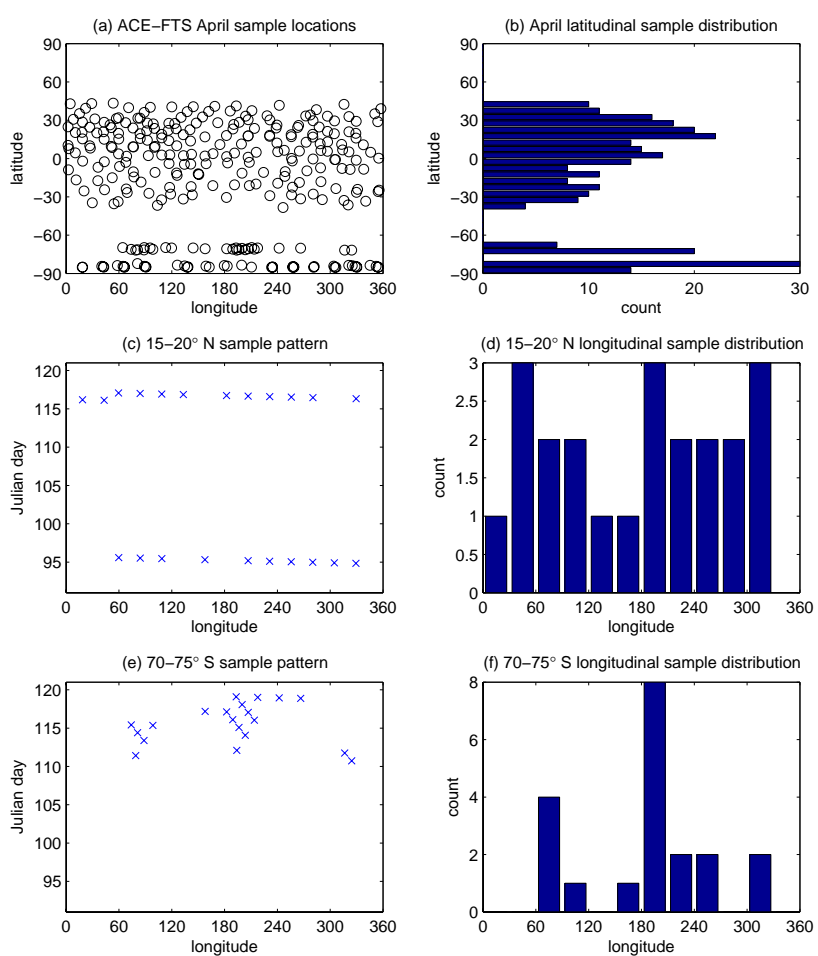

Fig. 4. ACE-FTS sampling from April 2005. (a) Full monthly sampling spatial pattern, (b) monthly sample counts per $5^{\circ}$ latitude bin, (c) time, longitude pattern of samples and (d) zonal sample distribution for the $15-20^{\circ} \mathrm{N}$ latitude bin, (e) time, longitude pattern of samples and (f) zonal sample distribution for the $70-75^{\circ} \mathrm{S}$ latitude bin.

(1997), respectively. Simulated chemical fields from a single year (1996) of the CMAM REF1 simulation described by Eyring et al. (2006) are used here. The chemical fields are available for every model gridpoint with $3.75^{\circ}$ by $3.75^{\circ}$ resolution in intervals of $18 \mathrm{~h}$.

The distributions of chemical species in the CMAM have been seen to generally compare well with observations (e.g. de Grandpré et al., 2000; Farahani et al., 2007; Hegglin and Shepherd, 2007; Jin et al., 2005; Jin et al., 2009; Melo et al., 2008). While this version of CMAM does not simulate the quasi-biennial oscillation and, thus, underestimates interannual variability in the tropics, the intra-month variability appears to be of realistic magnitude (see Chapter 7 of SPARC CCMVal, 2010; Toohey et al., 2010). The persistence (i.e., autocorrelation) of zonal mean $\mathrm{O}_{3}$ anomalies in CMAM agrees extremely well with observations, with interannual anomalies established through winter and spring persisting with very high correlation coefficients through summer until early autumn (Tegtmeier and Shepherd, 2007).

Figure 5 shows the monthly mean zonal mean $\mathrm{O}_{3}$ distribution for March, as well as the monthly zonal standard deviation (SD) for each latitude and height. Maxima in short-term (intra-monthly) $\mathrm{O}_{3}$ variability are found generally where
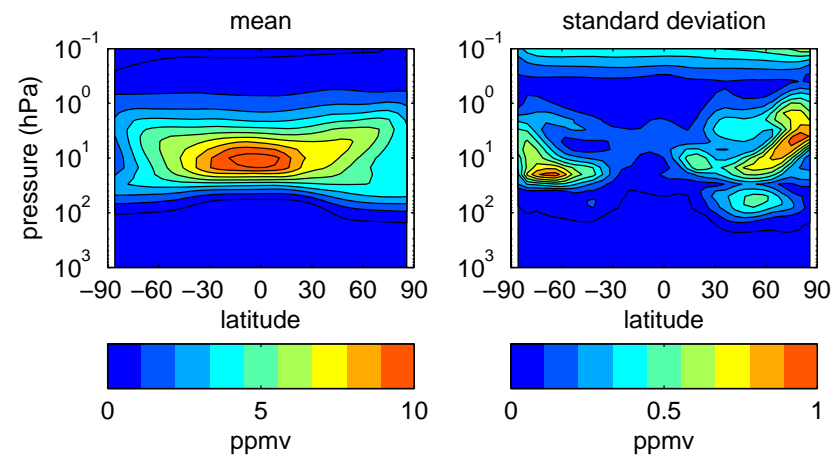

Fig. 5. CMAM March $\mathrm{O}_{3}$ : (left) monthly mean zonal mean $\mathrm{O}_{3}$ and (right) monthly zonal standard deviation $\mathrm{O}_{3}$ as function of latitude and pressure.

spatial gradients in $\mathrm{O}_{3}$ are strong. Variability is generally weak during summer months, therefore, examining variability around the equinoxes allows for a case when there is appreciable variability in both hemispheres.

\subsubsection{Measurement random errors}

MIPAS random error estimates for $\mathrm{O}_{3}$ measurements during the HR period are taken from the absolute values reported by Fig. 3 of Steck et al. (2007) and for the LR period from Table 7 of von Clarmann et al. (2009b). The random error estimates for the two periods are roughly similar, with slightly larger random errors reported for the HR period. For example, absolute values of random error peak around $30 \mathrm{~km}$, with values of approximately $0.35 \mathrm{ppmv}$ for the HR period, and 0.3 ppmv for the LR period: percent random error between approximately 20 and $40 \mathrm{~km}$ altitudes are reported as 5-6\% for the HR period and 4-5\% for the LR period.

ACE-FTS random error estimates for $\mathrm{O}_{3}$ are taken as the root-mean-square of the random errors reported in ACE-FTS v2.2 $\mathrm{O}_{3}$ update dataset for the month of March 2005. This random error profile is approximately equal to the profile reported for tropical retrievals shown in Fig. 6a of Toohey et al. (2010), with peak value of approximately $0.15 \mathrm{ppmv}$ around $30 \mathrm{~km}$, and percent values of $1-2 \%$ between 20 and $60 \mathrm{~km}$. It should be noted that the reported random errors of the ACEFTS measurements consider only measurement noise, and not other factors (e.g., pointing uncertainty) that may also lead to random errors in the retrieved profiles.

\subsection{Sampling procedure}

Given the measurement sampling patterns and model fields described above, the resampling experiment was performed as follows: for each sample (defined by its latitude, longitude and time), the closest model timestep was found, and the model fields for this timestep were linearly interpolated to the sample latitude and longitude. To produce an ensemble of "equivalent" sampling patterns, the original sampling 
(a) $\sigma_{\tau} \mathrm{N}^{-1 / 2}$

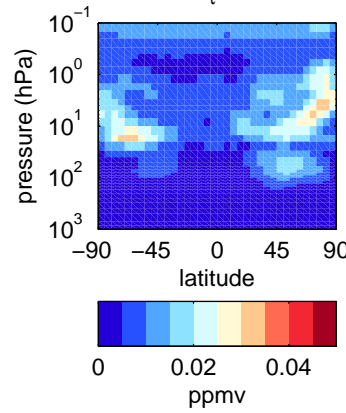

(e) $\sigma_{\tau} \mathrm{N}^{-1 / 2}$

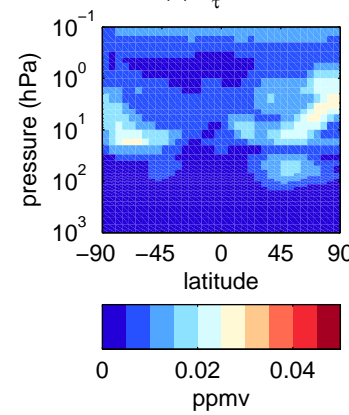

(b) $\sigma_{\varepsilon} \mathrm{N}^{-1 / 2}$

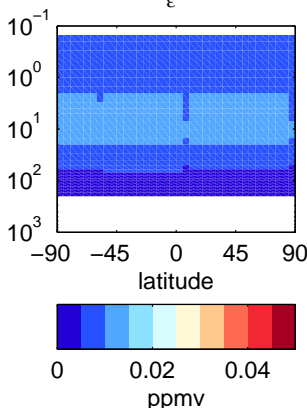

(f) $\sigma_{\varepsilon} \mathrm{N}^{-1 / 2}$

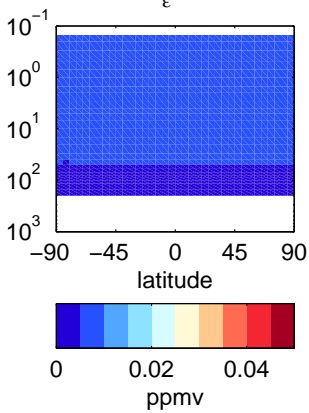

(c) SEM

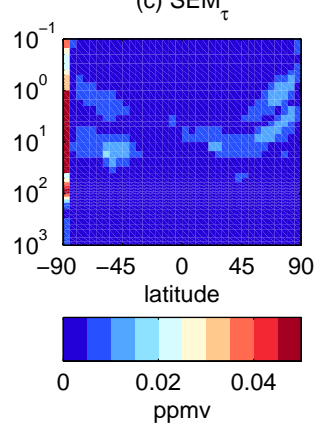

(g) SEM ${ }_{\tau}$

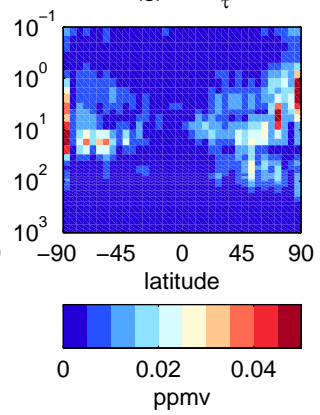

(d) $\mathrm{k}$
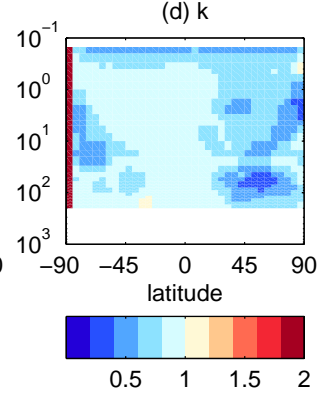

(h) k

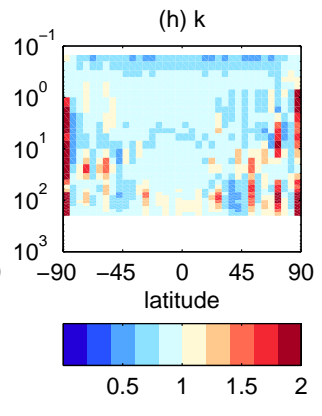

Fig. 6. Pressure latitude sections of zonal mean values of $\sigma_{\tau} / \sqrt{N}$, the single-sample estimate of the natural variability component of the SEM (first column); $\sigma_{\epsilon} / \sqrt{N}$, the random measurement error component of the SEM (second column); the empirically derived SEM (third column) and $k$ as defined in text (fourth column) based on MIPAS-HR (top) and MIPAS-LR (bottom) sampling of CMAM March $\mathrm{O}_{3}$.

pattern was adjusted by producing a random number $y$ from the uniform distribution over the interval $(0,1)$ and adding a term $360 y$ to the vector of longitudes, and subtracting $24 y$ from the time vector. Twenty ensemble members were created for each sampling pattern, and used to sample the model fields.

Given the $18 \mathrm{~h}$ temporal resolution of the model fields used here, we expect this sampling exercise to be valid only for long-lived chemical species. Variations of $\mathrm{O}_{3}$, which has a lifetime of days to weeks in the lower and middle stratosphere, should be adequately described by $18 \mathrm{~h}$ fields except in the upper stratosphere and mesosphere where diurnal variations become important. Application of the sampling experiment to other chemical species with shorter lifetimes would require the use of model fields with higher temporal resolution.

In general, the variability of sampled atmospheric fields depends on the resolution of the sample, with many processes (gravity waves, for example) that produce variability on small scales which will have negligible impacts over larger scales. It is, therefore, important for the resolution of the sampled model fields to be similar to the resolution expected of the atmospheric measurements. In the present case, the horizontal resolution of the CMAM fields is $3.75^{\circ}$, or roughly $400 \mathrm{~km}$, which is comparable to the horizontal resolutions of the ACE-FTS (ca. $500 \mathrm{~km}$ ) and MIPAS (ca. $400 \mathrm{~km}$, von Clarmann et al., 2009a) measurements. For this reason we have performed no smoothing of the model fields, although this would be necessary in the case that the model fields were of significantly finer resolution than the measurements. It should also be noted that in order for the present exercise to to applied to nadir-sounding instruments with fine horizontal resolution, model fields with similarly fine resolution would be required.

\subsection{Results}

\subsubsection{MIPAS}

Figure 6a-d shows results of the resampling exercise for MIPAS-HR sampling of $\mathrm{O}_{3}$ over the month of March. Figure 6a shows the sample SD divided by the square root of sample size, corresponding to a single-sample estimate of $\mathrm{SEM}_{\tau}$. This quantity follows the natural variability of the $\mathrm{O}_{3}$ field, with maximum values of $\sim 0.03 \mathrm{ppmv}$ in the mid- to high latitudes of the middle stratosphere, reflecting the ratio of maximum model variability ( $\sim 1$ ppmv, see Fig. 5 ) to the square root of the sample size $(\sim 800)$.

The SEM due to measurement error, $\sigma_{\epsilon} / \sqrt{N}$, is shown in Fig. 6b. This quantity is comparable in magnitude to that shown in $6 \mathrm{a}$, except in regions where natural variability reaches its maximum values.

The $\mathrm{SEM}_{\tau}$ estimated through the ensemble resampling technique (Fig. 6c) is notably smaller than $\sigma_{\tau} / \sqrt{N}$ (Fig. 6a) for almost all latitudes and heights. Given the rather uniform 

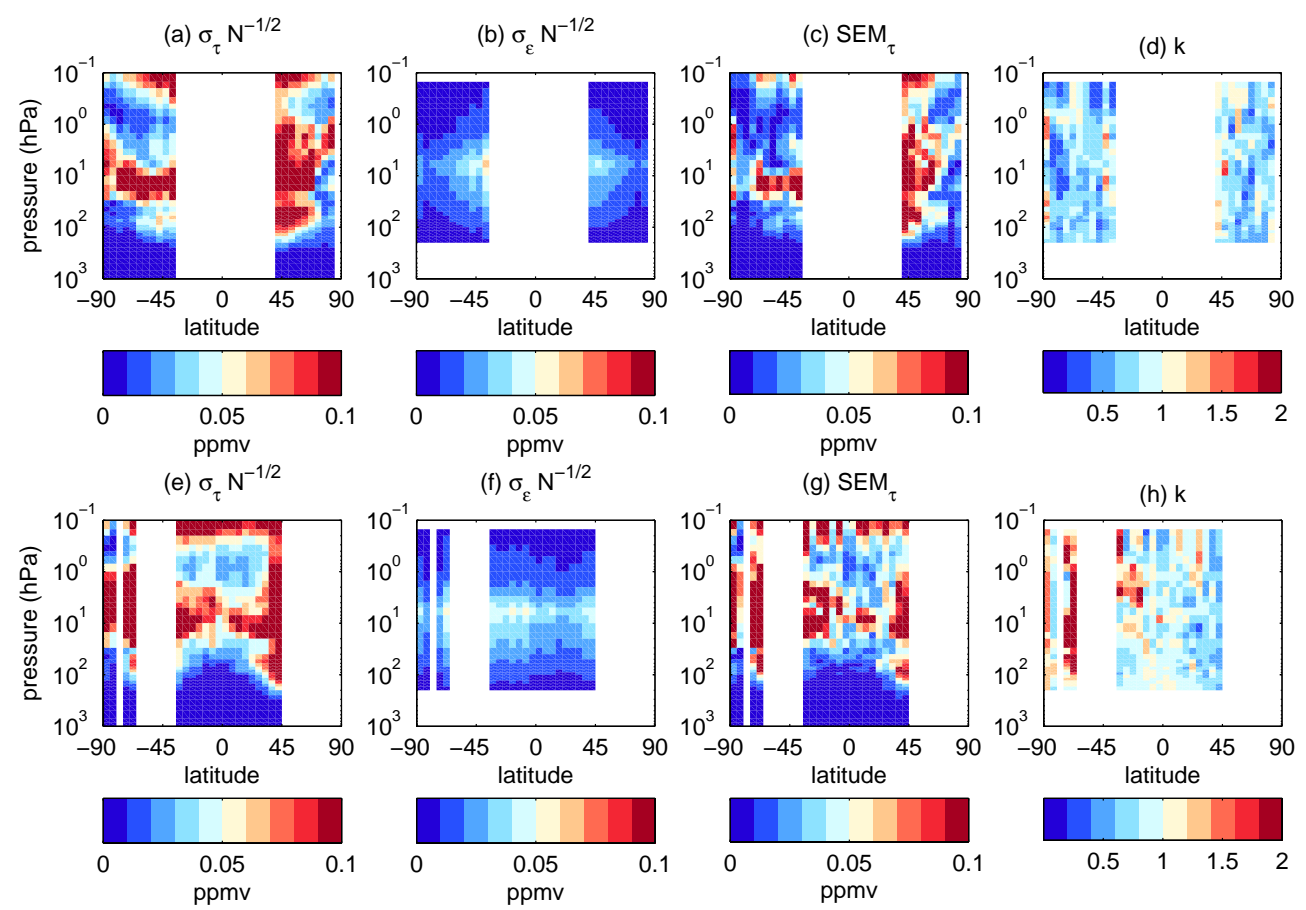

Fig. 7. Pressure latitude sections of zonal mean values of $\sigma_{\tau} / \sqrt{N}$, the single-sample estimate of the natural variability component of the SEM (first column); $\sigma_{\epsilon} / \sqrt{N}$, the random measurement error component of the SEM (second column); the empirically derived SEM $_{\tau}$ (third column) and $k$ as defined in text (fourth column) based on ACE-FTS sampling of CMAM March (top) and April (bottom) $\mathrm{O}_{3}$.

sampling pattern of MIPAS-HR, the sample mean is apparently quite insensitive to shifts in the longitudinal distribution. As a result, $k$ values (Fig. 6d) are less than 1 throughout almost all of the stratosphere. In regions where $\sigma_{\epsilon} / \sqrt{N}$ is greater than $\sigma_{\tau} / \sqrt{N}$, such as throughout most of the tropical stratosphere, $k$ values approach 1 . In regions of significant natural variability, i.e., in the mid- to high latitudes of both hemispheres, $k$ vales are small, reflecting the difference between $\sigma_{\tau} / \sqrt{N}$ and $\operatorname{SEM}_{\tau}$. In these regions the classic SEM estimator overestimates the true SEM given the MIPAS-HR sampling, in other words, in this case the classic SEM is a conservative estimate of the true SEM.

Figure $6 \mathrm{e}-\mathrm{h}$ shows results of the resampling exercise for MIPAS-LR sampling of $\mathrm{O}_{3}$ over March. Due to its larger sample sizes, $\sigma_{\tau} / \sqrt{N}$ (Fig. 6e) for MIPAS-LR sampling is slightly smaller than that for MIPAS-HR. The SEM due to measurement error, $\sigma_{\epsilon} / \sqrt{N}$ (Fig. 6f) is slightly smaller than its comparable quantity for the MIPAS-HR sampling due to larger sample sizes and the slightly smaller random error for the LR period retrievals. As for MIPAS-HR sampling, the $\mathrm{SEM}_{\tau}$ estimated through the ensemble resampling technique for MIPAS-LR sampling (Fig. $6 \mathrm{~g}$ ) is generally less than $\sigma_{\tau} / \sqrt{N}$, however, the results for MIPAS-LR sampling show a closer agreement between the two quantities than for MIPAS-HR. We interpret this result as a consequence of differences in the sampling patterns of the two MIPAS periods. With sampled latitudes within each bin varying from orbit to orbit, and the closer latitude spacing leading to occasional "double samples", MIPAS-LR sampling is a closer approximation of random sampling, therefore, it stands to reason that the $\mathrm{SEM}_{\tau}$ values estimated through the resampling exercise for MIPAS-LR are in closer agreement with $\sigma_{\tau} / \sqrt{N}$ than for MIPAS-HR.

For MIPAS-LR, in locations of significant natural variability there are also a handful of instances of notable local maxima in the $\mathrm{SEM}_{\tau}$ field, signifying cases where the sample mean is quite sensitive to longitudinal shifts in the sampling pattern. Such values are not reflected in the $\sigma_{\tau} / \sqrt{N}$ field, which leads to $k$ values greater than 1, with the implication that in these few cases, the classic SEM estimator, computed from any one sample set, would underestimate the true SEM.

\subsubsection{ACE-FTS}

Figure 7 shows results of the ensemble resampling exercise for ACE-FTS sampling of $\mathrm{O}_{3}$ over month of March and April. With much lower sample sizes than for MIPAS, $\sigma_{\tau} / \sqrt{N}$ (Fig. 7a and e) gives notably larger values than for MIPAS sampling (note different colour scale between Figs. 6 and 7). The random measurement errors of ACE-FTS measurements (Fig. 7b and f) are small compared to the natural variability and, as a result, the component of the SEM due to the random measurement noise is small compared to that due to sampled variability for most of the stratosphere. 
For March sampling, the $\mathrm{SEM}_{\tau}$ estimated through the ensemble resampling technique (Fig. 7c) is notably smaller than $\sigma_{\tau} / \sqrt{N}$ for almost all latitudes and heights. As a result, $k$ values (Fig. 7d) are less than one throughout much of the stratosphere. As for MIPAS-LR sampling, many $k$ values are relatively close to one, with $30 \%$ of $k$ values between 0.8 and 1.2. There also exist a few isolated instances of $k$ values greater than one, where the classic SEM estimator is seen to underestimate the SEM estimated through the resampling technique.

For April sampling, the SEM estimated through the ensemble resampling technique (Fig. $7 \mathrm{~g}$ ) is generally close in value or slightly less than the classic estimator, leading to $k$ values approximately equal to or less than one, with $36 \%$ of $k$ values between 0.8 and 1.2. Instances of $k>1$, where the classic SEM estimator is seen to underestimate the SEM estimated through the resampling technique, are more prevalent than found for March sampling, with large $k$ values found in the SH high latitudes and SH subtropics.

\subsection{Discussion}

Ignoring variations in sampling distribution with time, the resampling exercise used to produce the results in Figs. 6 and 7 can be simplified into the following: for each latitude bin, each resampled monthly mean value can be thought of as a weighted mean of the model zonal $\mathrm{O}_{3}$ field, where the weights are defined by the zonal distribution of the monthly sample number. Each ensemble member of the resampling exercise is then produced by randomly shifting the zonal sample distribution pattern with respect to the monthly mean $\mathrm{O}_{3}$ field. Variations in the monthly mean zonal mean sample means occur based on the relationship between the zonal structures of the $\mathrm{O}_{3}$ field and the sampling distribution - if either is completely uniform, then shifts in the relative zonal structure will have no effect on the sample mean. Furthermore, the degree to which the ensemble of sample means vary will depend on the similarity between the two distributions: maximum variation between ensemble member means should result when the mean $\mathrm{O}_{3}$ field and sample distribution have the same zonal structure.

This mechanism is explored in Fig. 8 for MIPAS-LR sampling. In Fig. 6h, it was seen that $k$ values greater than one were found in the Northern Hemisphere (NH) mid- to high latitudes, meaning that the SEM estimated though the resampling exercise was found to be larger than that estimated through the classical estimator. As an example case of large $k$ values, we examine the $50-55^{\circ} \mathrm{N}$ latitude bin at $60 \mathrm{hPa}$, a location of a local maximum in the $k$ values shown in Fig. 6h. Figure 8 shows a histogram of the sample distribution for the MIPAS-LR sampling pattern for the $50-55^{\circ} \mathrm{N}$ latitude bin separated into $30^{\circ}$ longitude bins. At this latitude, the MIPAS-LR sampling pattern has notable zonal structure, with a maximum and minimum in sample density separated by approximately $120^{\circ}$. Also shown is the

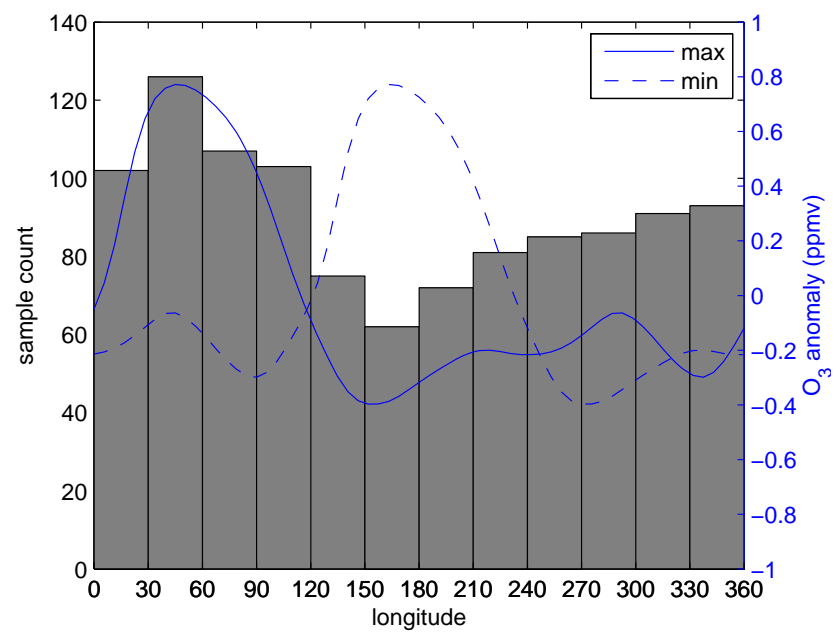

Fig. 8. Zonal MIPAS-LR sampling distribution for March within the $50-55^{\circ} \mathrm{N}$ latitude bin (gray bars). Also shown is the monthly mean zonal $\mathrm{O}_{3}$ anomaly field at $52.4^{\circ} \mathrm{N}$, at $20 \mathrm{hPa}$. The $\mathrm{O}_{3}$ field has been shifted in longitude to produce maximum (solid) and minimum (dashed) values of a weighted mean of the $\mathrm{O}_{3}$ field using the sample distribution as weights.

monthly mean zonal $\mathrm{O}_{3}$ anomaly field for the model latitude of $52^{\circ}$ at $60 \mathrm{hPa}$. The $\mathrm{O}_{3}$ field has been shifted in longitude to produce maximum (solid) and minimum (dashed) values of a weighted mean of the $\mathrm{O}_{3}$ field calculated by using the sample distribution as weights. There is a clear correspondence between the structures of the sampling distribution and the $\mathrm{O}_{3}$ field, and it follows that the sensitivity of the sample mean to the phasing of the sample distribution is related to the similarity between the two distributions.

In this way, the results of the sampling exercise can be seen to be related to the correlations between the zonal structures of the sample distribution and the measured field. The results of the sampling exercise can also be interpreted in terms of correlations between individual measurements. Equation (5) shows the relationship between $k$ and the mean correlation coefficient between all pairs of measurements. $k$ values less than 1 imply a negative mean correlation coefficient. For measured fields with a periodic structure in longitude, sampled with very uniform sampling, we might expect a negative correlation since every measurement is balanced by a corresponding measurement on the other side of the Earth. For non-uniform sampling, e.g., when some measurements are clustered around a certain longitude, then the similarity of the $\mathrm{O}_{3}$ field measured around this cluster leads to an increase in the mean correlation, leading to mean correlation coefficients approaching zero or reaching positive values, and correspondingly $k$ values of 1 or greater, as was found for the MIPAS-LR sampling at certain locations.

Figure 9 shows a similar explanatory plot for ACE-FTS. Maximum $k$ values for ACE-FTS sampling of $\mathrm{April}_{3}$ were found in the high SH latitudes (Fig. 7h). At these latitudes, 


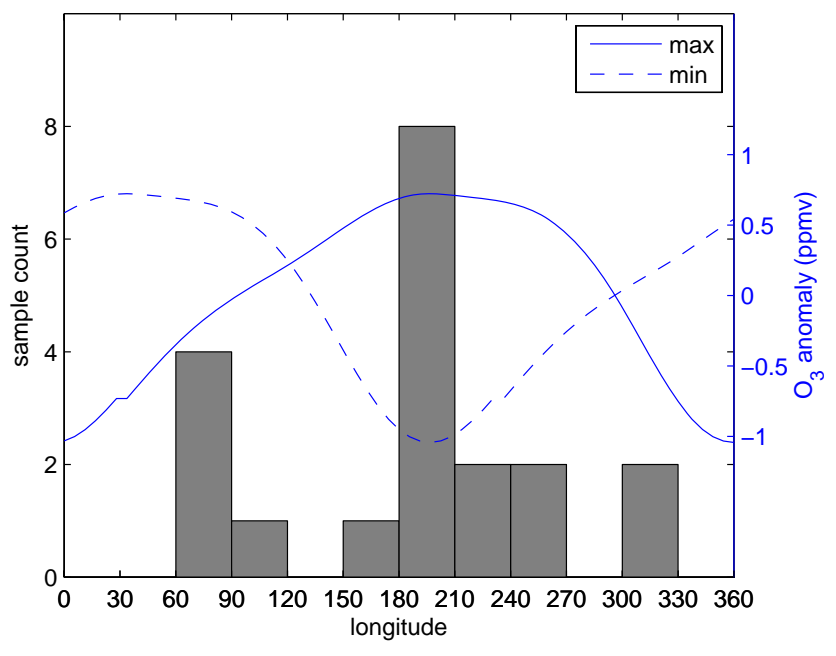

Fig. 9. Zonal ACE-FTS sampling distribution for March within the $70-75^{\circ} \mathrm{S}$ latitude bin (gray bars). Also shown is the monthly mean zonal $\mathrm{O}_{3}$ anomaly field at $74.7^{\circ} \mathrm{N}$, at $10 \mathrm{hPa}$. The $\mathrm{O}_{3}$ field has been shifted in longitude to produce maximum (solid) and minimum (dashed) values of a weighted mean of the $\mathrm{O}_{3}$ field using the sample distribution as weights.

the very large $k$ values are the result of a highly non-uniform sampling pattern with respect to longitude (as shown in Fig. 4), with most samples clustered within $120^{\circ}$ longitude of each other. As a result of this sampling pattern, any nonuniformity in the measured $\mathrm{O}_{3}$ field will lead to variations in the monthly mean zonal mean values produced by each realisation of the ensemble resampling, and as a result the SEM estimated by the resampling technique is large. Figure 9 shows the ACE-FTS sampling distribution for the $70-75^{\circ} \mathrm{S}$ latitude band, as well as the $\mathrm{O}_{3}$ anomaly field for this latitude at $10 \mathrm{hPa}$ over the days of ACE-FTS sampling of this latitude. $\mathrm{O}_{3}$ anomalies show clear zonally periodic variability at this latitude and height and, as a result, the sample mean is sensitive to the phase shift of the non-uniform sample distribution.

\section{Conclusions}

The usual way to estimate the standard error of the mean by division of the sample standard deviation by the square root of the sample size $\left(\sigma_{x} / \sqrt{N}\right)$ is exact only if the elements within the sample are uncorrelated. Satellite measurement datasets, however, are not random samples because measurement locations are the result of factors such as the regular satellite orbit and limitations of measurement frequency. Correlations between sampled points in the atmosphere may impact the measured variability such that the usual SEM estimator is inaccurate. By subsampling model data according to the real sampling patterns of two modern satellite-borne instruments, and incorporating information of the random errors of the instruments, this effect has been assessed for a number of test cases.

In cases where the random measurement error is larger than the natural variability, the classic SEM estimator should provide an accurate estimate of the uncertainty in the mean. However, when natural variability is larger than the random measurement error, the SEM may differ significantly from the classic estimator. Two cases with competing mechanisms have been discovered:

1. SEM $<\sigma_{x} / \sqrt{N}$ : this effect is most pronounced when the sample distribution is quite uniform with respect to longitude. Since variations of stratospheric trace gases such as $\mathrm{O}_{3}$ typically follow wave like patterns along zonal bands, within a zonal band, uniform sampling leads to negative mean correlation coefficients since each too-low measurement is compensated by a toohigh measurement. As a result, the classical SEM estimator, which assumes random sampling and not the highly uniform sampling of the satellite instrument overestimates the true standard error of the mean.

2. SEM $>\sigma_{x} / \sqrt{N}$ : this applies particularly to cases where the zonal sampling distribution is non-uniform. If the non-uniformity of the sampling pattern is of similar zonal structure to variations in the measured field, then the measured zonal mean is sensitive to arbitrary phase shifts between the sampling pattern and the measured field. As a result, the SEM is larger than that estimated by the classic estimator. In this case, the similar zonal structure of the sampling distribution and the measured field can be understood to result in positive mean correlation between samples, which we suggest is an equivalent explanation for the fact that the classical SEM underestimates the true SEM.

For satellite instruments with high sample density, such as MIPAS, isolated instances where the SEM calculated through the classic estimator is a factor of 2 too small may have very little practical importance. With such large sample sizes, the standard error of climatological means is practically so small that any differences between two such instruments is very likely dominated by systematic errors rather than random errors. However, for instruments with much smaller sample sizes, such as the solar occultation instrument ACE-FTS, proper interpretation of inter-instrument or instrument-model comparisons may rely more heavily on the calculation of an appropriate SEM. In such cases, the results of this study suggest that in order for the classic SEM estimator to be used, a climatology producer should be encouraged to require some degree of zonal uniformity in the sample distribution of measurements used to calculate a zonal mean. In fact, we find that the classic SEM may be still valid (or even a conservative estimate) for quite small sample sizes (e.g., under 10), as long as the zonal sample distribution is relatively uniform. 
Acknowledgements. The authors thank the instrument teams of MIPAS and ACE-FTS for providing sample patterns for use in this study, as well as Andreas I. Jonsson and Theodore G. Shepherd for providing the CMAM chemical fields. The Atmospheric Chemistry Experiment (ACE), also known as SCISAT-1, is a Canadian-led mission mainly supported by the Canadian Space Agency (CSA) and the Natural Sciences and Engineering Research Council (NSERC) of Canada. The CMAM is supported by the Canadian Foundation for Climate and Atmospheric Sciences and the CSA. M. T. acknowledges partial support through the EU project SHIVA (grant number 226224). This work was motivated by discussions within the SPARC Data initiative: the authors thank co-leaders Michaela Hegglin and Susann Tegtmeier, and all members of the SPARC DI team. Also thanks to Kaley Walker for helpful comments on a draft manuscript.

The service charges for this open access publication

have been covered by a Research Centre of the

Helmholtz Association.

Edited by: H. Worden

\section{References}

Aghedo, A. M., Bowman, K. W., Shindell, D. T., and Faluvegi, G.: The impact of orbital sampling, monthly averaging and vertical resolution on climate chemistry model evaluation with satellite observations, Atmos. Chem. Phys., 11, 6493-6514, doi:10.5194/acp-11-6493-2011, 2011.

Beagley, S. R., de Grandpré, J., Koshyk, J. N., McFarlane, N. A., and Shepherd, T. G.: Radiative-dynamical climatology of the first-generation Canadian Middle Atmosphere Model, Atmos. Ocean, 35, 293-331, doi:10.1080/07055900.1997.9649595, 1997.

Bernath, P. F., McElroy, C. T., Abrams, M. C., Boone, C. D., Butler, M., Camy-Peyret, C., Carleer, M., Clerbaux, C., Coheur, P.-F., Colin, R., DeCola, P., DeMazière, M., Drummond, J. R., Dufour, D., Evans, W. F. J., Fast, H., Fussen, D., Gilbert, K., Jennings, D. E., Llewellyn, E. J., Lowe, R. P., Mahieu, E., McConnell, J. C., McHugh, M., McLeod, S. D., Michaud, R., Midwinter, C., Nassar, R., Nichitiu, F., Nowlan, C., Rinsland, C. P., Rochon, Y. J., Rowlands, N., Semeniuk, K., Simon, P., Skelton, R., Sloan, J. J., Soucy, M.-A., Strong, K., Tremblay, P., Turnbull, D., Walker, K. A., Walkty, I., Wardle, D. A., Wehrle, V., Zander, R., and Zou, J.: Atmospheric Chemistry Experiment (ACE): Mission overview, Geophys. Res. Lett., 32, L15S01, doi:10.1029/2005GL022386, 2005.

de Grandpré, J., Sandilands, J. W., Mcconnell, J. C., Beagley, S. R., Croteau, P. C., and Danilin, M. Y.: Canadian Middle Atmosphere Model: Preliminary results from the chemical transport module, Atmosphere-Ocean, 35, 385-431, doi:10.1080/07055900.1997.9649598, 1997.

de Grandpré, J., Beagley, S. R., Fomichev, V. I., Griffioen, E., McConnell, J. C., Medvedev, A. S., and Shepherd, T. G.: Ozone climatology using interactive chemistry: Results from the Canadian Middle Atmosphere Model, J. Geophys. Res., 105, 2647526492, doi:10.1029/2000JD900427, 2000.

Eyring, V., Butchart, N., Waugh, D. W., Akiyoshi, H., Austin, J., Bekki, S., Bodeker, G. E., Boville, B. A., Brühl, C., Chipper- field, M. P., Cordero, E., Dameris, M., Deushi, M., Fioletov, V. E., Frith, S. M., Garcia, R. R., Gettelman, A., Giorgetta, M. A., Grewe, V., Jourdain, L., Kinnison, D. E., Mancini, E., Manzini, E., Marchand, M., Marsh, D. R., Nagashima, T., Newman, P. A., Nielsen, J. E., Pawson, S., Pitari, G., Plummer, D. A., Rozanov, E., Schraner, M., Shepherd, T. G., Shibata, K., Stolarski, R. S., Struthers, H., Tian, W., and Yoshiki, M.: Assessment of temperature, trace species, and ozone in chemistry-climate model simulations of the recent past, J. Geophys. Res., 111, D22308, doi:10.1029/2006JD007327, 2006.

Farahani, E., Fast, H., Mittermeier, R. L., Makino, Y., Strong, K., McLandress, C., Shepherd, T. G., Chipperfield, M. P., Hannigan, J. W., Coffey, M. T., Mikuteit, S., Hase, F., Blumenstock, T., and Raffalski, U.: Nitric acid measurements at Eureka obtained in winter 2001-2002 using solar and lunar Fourier transform infrared absorption spectroscopy: Comparisons with observations at Thule and Kiruna and with results from three-dimensional models, J. Geophys. Res., 112, D01305, doi:10.1029/2006JD007096, 2007.

Fischer, H., Birk, M., Blom, C., Carli, B., Carlotti, M., von Clarmann, T., Delbouille, L., Dudhia, A., Ehhalt, D., Endemann, M., Flaud, J. M., Gessner, R., Kleinert, A., Koopman, R., Langen, J., López-Puertas, M., Mosner, P., Nett, H., Oelhaf, H., Perron, G., Remedios, J., Ridolfi, M., Stiller, G., and Zander, R.: MIPAS: an instrument for atmospheric and climate research, Atmos. Chem. Phys., 8, 2151-2188, doi:10.5194/acp-8-2151-2008, 2008.

Grooß, J.-U. and Russell III, J. M.: Technical note: A stratospheric climatology for $\mathrm{O}_{3}, \mathrm{H}_{2} \mathrm{O}, \mathrm{CH}_{4}, \mathrm{NO}_{\mathrm{x}}, \mathrm{HCl}$ and $\mathrm{HF}$ derived from HALOE measurements, Atmos. Chem. Phys., 5, 2797-2807, doi:10.5194/acp-5-2797-2005, 2005.

Hegglin, M. I. and Shepherd, T. G.: $\mathrm{O}_{3}-\mathrm{N}_{2} \mathrm{O}$ correlations from the Atmospheric Chemistry Experiment: Revisiting a diagnostic of transport and chemistry in the stratosphere, J. Geophys. Res., 112, 19301, doi:10.1029/2006JD008281, 2007.

Hegglin, M. I. and Tegtmeier, S.: The SPARC Data Initiative, SPARC Newsletter, 36, 22-23, available at: http: //www.sparc-climate.org/fileadmin/customer/6_Publications/ Newsletter_PDF/36_SPARCnewsletter_Jan2011.pdf (last access: 8 April 2013), 2011.

Jin, J. J., Semeniuk, K., Jonsson, A. I., Beagley, S. R., McConnell, J. C., Boone, C. D., Walker, K. A., Bernath, P. F., Rinsland, C. P., Dupuy, E., Ricaud, P., De La Noë, J., Urban, J., and Murtagh, D.: Co-located ACE-FTS and Odin/SMR stratospheric-mesospheric CO 2004 measurements and comparison with a GCM, Geophys. Res. Lett., 32, L15S03, doi:10.1029/2005GL022433, 2005.

Jin, J. J., Semeniuk, K., Beagley, S. R., Fomichev, V. I., Jonsson, A. I., McConnell, J. C., Urban, J., Murtagh, D., Manney, G. L., Boone, C. D., Bernath, P. F., Walker, K. A., Barret, B., Ricaud, P., and Dupuy, E.: Comparison of CMAM simulations of carbon monoxide $(\mathrm{CO})$, nitrous oxide $\left(\mathrm{N}_{2} \mathrm{O}\right)$, and methane $\left(\mathrm{CH}_{4}\right)$ with observations from Odin/SMR, ACE-FTS, and Aura/MLS, Atmos. Chem. Phys., 9, 3233-3252, doi:10.5194/acp-9-3233-2009, 2009.

Jones, P. D., Osborn, T. J., and Briffa, K. R.: Estimating sampling errors in large-scale temperature averages, J. Climate, 10, 2548-2568, doi:10.1175/15200442(1997)010;2548:ESEILS;2.0.CO;2, 1997.

Melo, S. M. L., Blatherwick, R., Davies, J., Fogal, P., de Grandpré, J., McConnell, J., McElroy, C. T., McLandress, C., Murcray, 
F. J., Olson, J. R., Semeniuk, K., Shepherd, T. G., Strong, K., Tarasick, D., and Williams-Rioux, B. J.: Summertime stratospheric processes at northern mid-latitudes: comparisons between MANTRA balloon measurements and the Canadian Middle Atmosphere Model, Atmos. Chem. Phys., 8, 2057-2071, doi:10.5194/acp-8-2057-2008, 2008.

SPARC CCMVal: SPARC Report on the Evaluation of ChemistryClimate Models, edited by: Eyring, V., Shepherd, T. G., and Waugh, D. W., SPARC Report No. 5, WCRP-132, WMO/TD-No. 1526, available at: http://www.sparc-climate. org/publications/sparc-reports/sparc-report-no5/ (last access: 8 April 2013), 2010.

Steck, T., von Clarmann, T., Fischer, H., Funke, B., Glatthor, N., Grabowski, U., Höpfner, M., Kellmann, S., Kiefer, M., Linden, A., Milz, M., Stiller, G. P., Wang, D. Y., Allaart, M., Blumenstock, Th., von der Gathen, P., Hansen, G., Hase, F., Hochschild, G., Kopp, G., Kyrö, E., Oelhaf, H., Raffalski, U., Redondas Marrero, A., Remsberg, E., Russell III, J., Stebel, K., Steinbrecht, W., Wetzel, G., Yela, M., and Zhang, G.: Bias determination and precision validation of ozone profiles from MIPAS-Envisat retrieved with the IMK-IAA processor, Atmos. Chem. Phys., 7, 3639-3662, doi:10.5194/acp-7-3639-2007, 2007.

Tegtmeier, S. and Shepherd, T. G.: Persistence and photochemical decay of springtime total ozone anomalies in the Canadian Middle Atmosphere Model, Atmos. Chem. Phys. Discuss., 6, 3403 3417, doi:10.5194/acpd-6-3403-2006, 2006.

Toohey, M., Strong, K., Bernath, P. F., Boone, C. D., Walker, K. A., Jonsson, A. I., and Shepherd, T. G.: Validating the reported random errors of ACE-FTS measurements, J. Geophys. Res., 115, D20304, doi:10.1029/2010JD014185, 2010. von Clarmann, T., De Clercq, C., Ridolfi, M., Höpfner, M., and Lambert, J.-C.: The horizontal resolution of MIPAS, Atmos. Meas. Tech., 2, 47-54, doi:10.5194/amt-2-47-2009, 2009a.

von Clarmann, T., Höpfner, M., Kellmann, S., Linden, A., Chauhan, S., Funke, B., Grabowski, U., Glatthor, N., Kiefer, M., Schieferdecker, T., Stiller, G. P., and Versick, S.: Retrieval of temperature, $\mathrm{H}_{2} \mathrm{O}, \mathrm{O}_{3}, \mathrm{HNO}_{3}, \mathrm{CH}_{4}, \mathrm{~N}_{2} \mathrm{O}, \mathrm{ClONO}_{2}$ and $\mathrm{ClO}$ from MIPAS reduced resolution nominal mode limb emission measurements, Atmos. Meas. Tech., 2, 159-175, doi:10.5194/amt-2-159-2009, 2009 b.

von Clarmann, T., Stiller, G., Grabowski, U., Eckert, E., and Orphal, J.: Technical Note: Trend estimation from irregularly sampled, correlated data, Atmos. Chem. Phys., 10, 6737-6747, doi:10.5194/acp-10-6737-2010, 2010.

von Clarmann, T., Funke, B., Glatthor, N., Kellmann, S., Kiefer, M., Kirner, O., Sinnhuber, B.-M., and Stiller, G. P.: The MIPAS HOCl climatology, Atmos. Chem. Phys., 12, 1965-1977, doi:10.5194/acp-12-1965-2012, 2012.

Weatherhead, E. C., Reinsel, G. C., Tiao, G. C., Meng, X.-L., Choi, D., Cheang, W.-K., Keller, T., DeLuisi, J., Wuebbles, D. J., Kerr, J. B., Miller, A. J., Oltmans, S. J., and Frederick, F. E.: Factors affecting the detection of trends: Statistical considerations and applications to environmental data, J. Geophys. Res., 103, 17149-17161, doi:10.1029/98JD00995, 1998. 